\title{
Chuvas intensas para projetos de conservação do solo e da água no estado de Santa Catarina
}

\author{
Álvaro José Back'; Leandro do Prado Wildner² e Jóri Ramos Pereira³
}

\begin{abstract}
Resumo - Para o dimensionamento de estruturas para conservação do solo e água é imprescindível conhecer o valor da chuva intensa de cada local. O presente trabalho teve como objetivo determinar o valor representativo das chuvas intensas a ser usado em projetos de conservação do solo e água para todos os municípios do estado de Santa Catarina. Foram utilizadas séries históricas de 162 estações pluviométricas que possuíam mais de 30 anos de dados, incluindo o período após o ano 2000. Para cada estação foram ajustados os parâmetros da distribuição GEV e Gumbel. Com a distribuição que apresentou melhor ajuste foram estimados os valores de chuva máxima com período de retorno de 10 anos. Estes dados foram espacializados, usando o método da Krigagem, e obtidos os valores médios representativos para cada município catarinense. Os resultados mostram uma variação espacial da chuva intensa no Estado, com maiores valores nas Regiões do Extremo Oeste, Litoral Centro e Litoral Norte, e menores no Alto Vale do Itajaí. Para o período de retorno de 10 anos a chuva máxima diária variou de 104,9 a $157,1 \mathrm{~mm}$, enquanto a intensidade da chuva com duração de 15 minutos variou de 93,2 a 139,5 $\mathrm{mm} \mathrm{h}^{-1}$.
\end{abstract}

Termos de indexação: Terraços; Erosão; Drenagem agrícola; Terraceamento.

\section{Heavy rains for soil conservation projects in the state of Santa Catarina}

\begin{abstract}
In order to design structures for soil and water conservation, it is essential to know the value of intense rain in each location. The present work had as objective to determine the representative value of the intense rains to be used in projects of conservation of the soil and water for all the municipalities of the state of Santa Catarina. Series of 162 pluviometric stations were used that had more than 30 years of data, including the period after the year 2000 . For each station the parameters of the GEV and Gumbel distribution were adjusted. With the distribution that showed the best adjustment, the maximum rainfall values with a 10-year return period were estimated. These data were spatialized using the Krigagem method and the representative average values were obtained for each municipality in Santa Catarina. The results show a spatial variation of intense rain in the state, with higher values in the Regions of the Far West, Central Coast and North Coast, and lower in the Alto Vale do Itajaí. For the 10-year return period, the maximum daily rainfall ranged from 104.9 to $157.1 \mathrm{~mm}$, and the intensity of the rain lasting 15 minutes ranged from 93.2 to $139.5 \mathrm{~mm} \mathrm{~h}^{-1}$.
\end{abstract}

Index terms: Terraces; Erosion; Agricultural drainage; Terracing.

\section{Introdução}

As chuvas intensas causam problemas de escoamento superficial e alagamento, podendo resultar em prejuízos tanto no meio urbano como no meio rural. Nas áreas de produção agrícola, chuvas intensas ou o excesso de chuva causam erosão hídrica e perdas de solo. A erosão, além de degradar o solo, reduzindo sua produtividade e a produção das culturas, tem como problemas adicionais a contaminação das águas e o assoreamento de rios e reservatórios (ALVES SOBRINHO et al., 2011; ALMEIDA et al., 2012).
Para contornar estes problemas e melhorar a qualidade do solo são recomendadas práticas de conservação do solo que atuam diretamente na mitigação da ação da chuva sobre o solo, tais como a cobertura permanente e a diversificação de culturas, estruturadas na sucessão, rotação e consorciação de espécies, assim como práticas complementares que atuam na redução do escoamento superficial, como o cultivo em contorno e o terraceamento. A construção de terraços requer planejamento e dimensionamento adequado (BERTONI \& LOMBARDI NETO, 2012).
Quando planejados terraços em gradiente, deve-se também dimensionar o canal escoadouro, bem como bueiros e outros canais à jusante.

Para cada tipo de estrutura ou obra de engenharia existem diferentes critérios de dimensionamento que são baseados em diferentes informações da chuva intensa. $O$ dimensionamento dos terraços em nível, por exemplo, é realizado com base na chuva máxima com duração de 24 horas (ASAE, 2012). Já para terraços em gradiente é comum o uso da intensidade máxima da chuva com duração de 15 minutos (DE MARIA

Recebido em 9/3/2021. Aceito para publicação em 14/6/2021.

http//:dx.doi.org/10.52945/rac.v34i2.1140

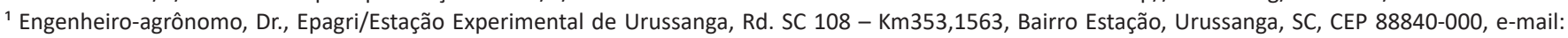
ajb@epagri.sc.gov.br

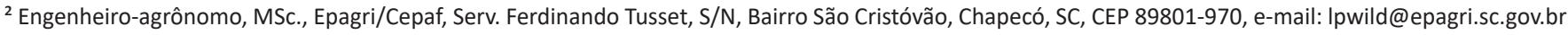

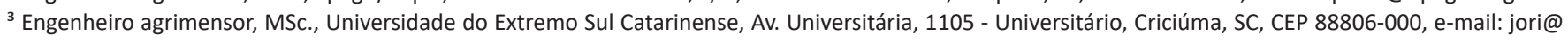
unesc.net 
et al., 2016). O período de retorno está relacionado ao risco e ao custo da obra, sendo indicado para projetos de conservação de solos e drenagem de superfície de áreas agrícolas, com valores da ordem de 5 a 20 anos (GRIEBELER et al., 2001; BERTONI \& LOMBARDI NETO, 2012).

Informações relativas a chuvas intensas do local da obra são fundamentais para o planejamento e para o dimensionamento das estruturas de captação e condução da água. A caracterização da chuva local é realizada com base na análise das frequências de eventos extremos observados nas séries históricas de pluviosidade.

$\mathrm{Na}$ análise de frequências deve-se ajustar uma distribuição teórica de probabilidades baseada na série de chuvas máximas observadas no local. Existem várias distribuições de probabilidade que podem ser usadas, destacando-se a Distribuição de Extremos Tipo I e a Distribuição Generalizada de Valores Extremos (GEV). A Distribuição de Extemos Tipo I, também conhecida com Distribuição de Gumbel, é largamente usada para a estimativa das chuvas máximas (BACK, 2013; MARQUES et al., 2014; MISTRY \& SURYANARAYANA, 2019), enquanto a distribuição GEV é adotada para estimar eventos extremos de precipitação (MARRA et al., 2017).

Este trabalho teve como objetivo determinar o valor representativo das chuvas intensas a ser usado em projetos de conservação de solo e água para todos os municípios do estado de Santa Catarina.

\section{Material e métodos}

Foram analisadas as séries históricas das estações pluviométricas localizadas no estado de Santa Catarina pertencentes à rede de estações pluviométricas da Agência Nacional de Águas - ANA (ANA, 2020) e à rede de estações pluviométricas da Empresa de Pesquisa Agropecuária e Extensão Rural de Santa Catarina (EPAGRI, 2020). Algumas estações pluviométricas da Epagri, denominadas de convencionais, em que a observação da precipitação era realizada por pluviô- metros, foram substituídas por estações automáticas. Nestes casos, foi utilizada a série existente, com dados convencionais, e complementada com a série das estações automáticas.

As séries de máximas anuais de chuvas diárias foram determinadas considerando cada ano a partir do calendário civil; os anos que apresentaram falhas de dados foram excluídos da série de máximas.

Neste estudo, foram consideradas somente as estações com mais de 30 anos de dados, excluindo-se as estações que tinham somente dados anteriores ao ano 2000. Considerando este critério foram, então, selecionadas 162 estações pluviométricas, sendo 20 estações da Epagri e 142 da ANA (Figura 1).

Para cada série foram ajustados os parâmetros da distribuição Gumbel e GEV pelos métodos dos Momentos (KITE, 1978), Máxima Verossimilhança (KITE, 1978) e L-Moments (HOSKING, 1990). Para a distribuição Gumbel ainda foram ajustados os parâmetros pelo método de Chow (BACK, 2013), totalizando sete distribuições para cada série de dados.

Para testar a aderência das séries às distribuições teóricas ajustadas, foram usados os testes de aderência de Kolmogorov-Smirnov (KS) (KITE, 1978), Anderson-Darling (AD) (BESKOW et al., 2015) e R de Filliben (RF) (FILLIBEN, 1975). Para avaliar a qualidade do ajuste ainda foi considerado o erro padrão de estimativa (EP), conforme descrito em Kite (1978). A seleção da melhor distribuição de probabilidades foi realizada pelo ranqueamento das distribuições, com valores de 1 a 7 , em que os menores valores de KS, AD, EP e os maiores valores de RF recebem o menor escore. Dessa forma, cada série pode receber o escore variando de 4 a 28 , sendo selecionada a distribuição com o menor escore global. Com a melhor distribuição de probabilidades foram estimadas as chuvas máximas diárias para período de retorno de 10 anos.

Para avaliar a variação espacial da chuva extrema diária, foi gerado o mapa de chuva máxima diária com o uso do ArcGIS 10.2.1 - Spatial Analyst, que fornece um conjunto de ferramentas para modelagens espaciais. Após a modelagem, foram obtidas as médias dos valores para cada município por meio da ferramenta Zonal Statistics, cruzando as informações espaciais entre o shapefile dos municípios e o raster resultado da Krigagem.

\section{Resultados e discussão}

Na Figura 2, pode-se visualizar a distribuição espacial das chuvas extremas diárias com período e retorno de 10 anos no estado de Santa Catarina, em que os valores variam de 100 a $160 \mathrm{~mm}$. Este é o período de retorno recomendado para dimensionamento de obras de conservação do solo e água, não só no

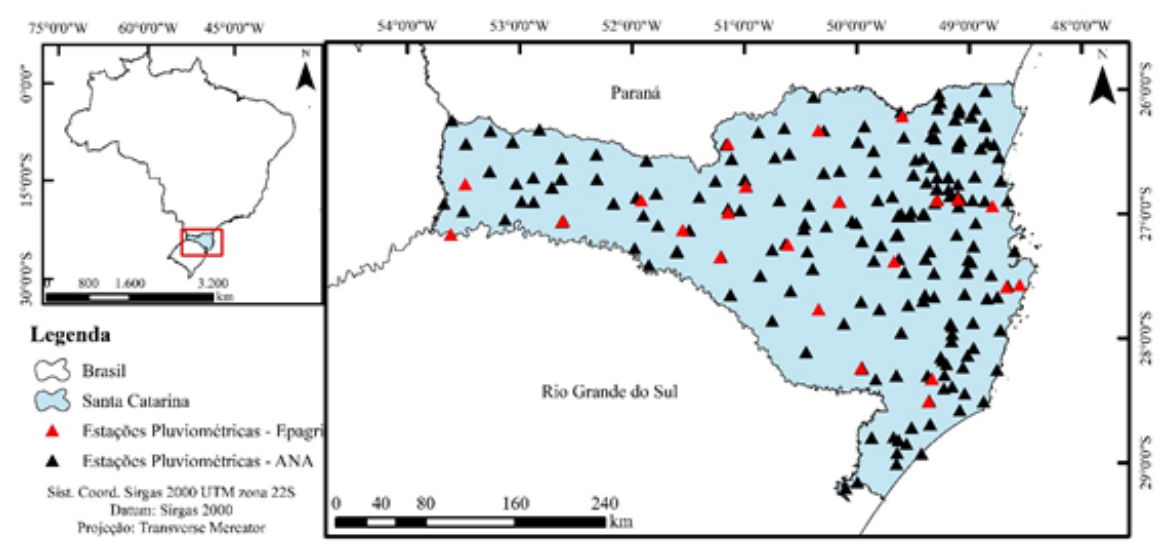

Figura 1. Distribuição espacial das 162 estações pluviométricas séries de dados superior a 30 anos, localizadas no estado de Santa Catarina, Brasil

Figure 1. Spatial distribution of 162 pluviometric stations data series over 30 years, located in the state of Santa Catarina, Brazil 


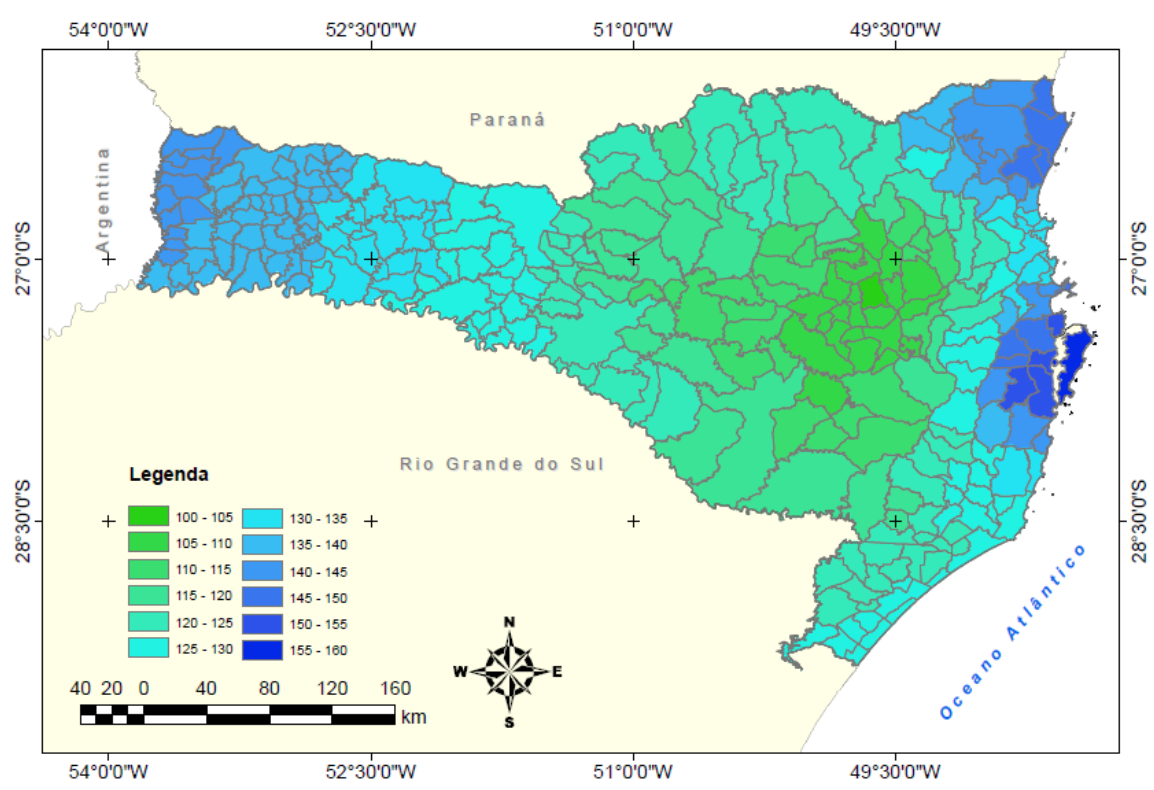

Figura 2. Chuva máxima diária com período de retorno de10 anos para o estado de Santa Catarina, estimada com base em 162 estações pluviométricas com séries de dados superior a 30 anos

Figure 2. Maximum daily rainfall with a return period of 10 years for the state of Santa Catarina, estimated based on 162 rainfall stations with data series over 30 years

Brasil (CRUCIANI, 1989; DE MARIA et al., 2016) como em vários outros países (KESSLER \& RAAD, 1978; SCHWAB et al., 1981; RAMIREZ CRUZ et al., 2015).

Pode-se observar uma variação espacial relativamente bem definida, com valores maiores no Extremo Oeste e na região do litoral, especialmente na região de Florianópolis, e menores no Alto Vale do Itajaí. Resultados semeIhantes foram descritos por Back et al. (2016). Essa distribuição de chuvas máximas está de acordo com a variação espacial de chuvas médias anuais no Estado, descritas em vários trabalhos (BACK, 2001; COAN et al., 2014; BACK \& POLETO, 2018; e GOTARDO et al., 2018). A variação espacial das chuvas no estado de Santa Catarina é explicada principalmente pela atuação diferenciada das massas de ar e, também, devido ao relevo (ORSELLI, 1991; MONTEIRO \& FURTADO, 1995; MONTEIRO, 2001; REBIOTA et al., 2010). As regiões Nordeste e Leste também foram marcadas por altos índices pluviométricos devido às condições geomorfológicas que favorecem a ocorrência de chuvas orográficas
(MONTEIRO, 2001).

As perdas de solo por erosão dependem de cinco fatores principais: fator chuva - R (Erosividade da chuva); fator solo - K (erodibilidade do solo); fator topografia - LS (comprimento e inclinação do terreno); fator cultivo e manejo do solo - C; e, fator práticas conservacionistas - P (LAFLEN \& MOLDENHAUER, 2003). Na inter-relação desses fatores, $O$ potencial erosivo da chuva e as características topográficas da área constituem o componente energético capaz de produzir erosão; por isso o princípio básico do controle da erosão hídrica está associado à dissipação da energia cinética da gota da chuva e à redução da energia ciDIN et al., 2005). Para o controle da enxurrada é imperativo o uso de práticas mecânicas, em especial o terraço, cujas dimensões devem estar relacionadas à ocorrência de chuvas intensas em cada local específico de uso. Os resultados obtidos neste estudo mostram que na região do Extremo Oeste de Santa Catarina ocorrem eventos extremos com maior frequência, e assim as dimensões nética cisalhante da enxurrada (DENAR- das estruturas de captação e armazenamento de água, tais como terraços e canais de drenagem, devem ser maiores quando comparadas àquelas das regiões do Alto Vale e Planalto Serrano.

Na Tabela 1 constam os valores médios de chuvas máximas diárias anuais com período de retorno de 10 anos por município de Santa Catarina para uso em projetos de conservação do solo e da água. Os valores variam de 104,9 a $157,1 \mathrm{~mm}$. Os valores foram obtidos por geoprocessamento e, assim, são influenciados pelos valores observados nas estações pluviométricas próximas. Essa espacialização tem a vantagem de obter um valor prático a ser usado em municípios sem estações pluviométricas. Nos municípios em que existe mais de uma estação, como, por exemplo, Blumenau e Joinville, o uso do valor médio permite usar um valor único representativo do município.

Para dimensionamento de terraços em gradiente é recomendado o uso da intensidade da chuva com duração de 15 minutos e período de retorno de 10 anos. Para chuvas de menor duração pode-se utilizar os métodos de desagregação da chuva diária em chuva de menor duração (CETESB, 1986; BACK et al., 2013) ou por relações empíricas obtidas desses coeficientes. Dessa forma a chuva com duração de 15 minutos é obtida multiplicando-se a chuva máxima diária por um coeficiente que depende das relações entre as durações observadas. Para as relações médias observadas no Brasil (CETESB, 1986) esse coeficiente é 0,248 , já para as relações médias observadas em Santa Catarina (BACK, 2013) esse coeficiente é 0,222 . Na Tabela 1 constam os valores médios de intensidade da chuva com duração de $15 \mathrm{mi}-$ nutos e período de retorno de 10 anos aplicando-se o método das relações entre durações observadas em Santa Catarina. Os valores de intensidade da chuva com duração de 15 minutos e período de retorno de 10 anos variam de 93,2 a $135,5 \mathrm{~mm} \mathrm{~h}^{-1}$. Esse procedimento pode ser aplicado a outros períodos de retorno e/ou outras durações obtendo-se as respectivas intensidades. 
Tabela 1. Altura da chuva máxima diária $\left(\mathrm{P}_{1 \text { dia }}\right)$ e intensidade da chuva máxima com duração de 15 minutos $\left(\mathrm{I}_{15}\right)$ para período de retorno de 10 anos para os municípios catarinenses

Table 1. Height of maximum daily rainfall $\left(P_{1 \text { day }}\right)$ and intensity of maximum rainfall lasting 15 minutes $\left(I_{15}\right)$ for a 10-year return period for the municipalities of Santa Catarina

\begin{tabular}{|c|c|c|c|c|c|}
\hline Município & $\begin{array}{l}P_{1 \text { dia }} \\
(\mathrm{mm})\end{array}$ & $\mathrm{I}_{15}\left(\mathrm{~mm} \mathrm{~h}^{-1}\right)$ & Município & $\begin{array}{l}P_{1 \text { dia }} \\
(\mathrm{mm})\end{array}$ & $\mathrm{I}_{15}\left(\mathrm{~mm} \mathrm{~h}^{-1}\right)$ \\
\hline Abdon Batista & 123,3 & 109,5 & Bom Jardim Da Serra & 118,1 & 104,9 \\
\hline Abelardo Luz & 132,0 & 117,2 & Bom Jesus & 131,6 & 116,9 \\
\hline Agrolândia & 108,9 & 96,7 & Bom Jesus do Oeste & 138,1 & 122,7 \\
\hline Agronômica & 105,7 & 93,9 & Bom Retiro & 112,7 & 100,1 \\
\hline Água Doce & 125,8 & 111,7 & Bombinhas & 147,1 & 130,6 \\
\hline Águas de Chapecó & 135,8 & 120,5 & Botuverá & 117,7 & 104,5 \\
\hline Águas Frias & 135,2 & 120,0 & Braço do Norte & 125,2 & 111,2 \\
\hline Águas Mornas & 143,5 & 127,5 & Braço do Trombudo & 108,7 & 96,6 \\
\hline Alfredo Wagner & 116,3 & 103,3 & Brunópolis & 115,9 & 103,0 \\
\hline Alto Bela Vista & 127,5 & 113,2 & Brusque & 127,0 & 112,8 \\
\hline Anchieta & 139,9 & 124,2 & Caçador & 118,6 & 105,3 \\
\hline Angelina & 130,0 & 115,4 & Caibi & 136,2 & 120,9 \\
\hline Anita Garibaldi & 122,7 & 108,9 & Calmon & 118,9 & 105,6 \\
\hline Anitápolis & 126,1 & 112,0 & Camboriú & 131,7 & 116,9 \\
\hline Antônio Carlos & 149,1 & 132,4 & Campo Alegre & 139,0 & 123,4 \\
\hline Apiúna & 108,0 & 95,9 & Campo Belo do Sul & 120,2 & 106,7 \\
\hline Arabutã & 129,4 & 114,9 & Campo Erê & 139,8 & 124,2 \\
\hline Araquari & 146,9 & 130,4 & Campos Novos & 122,6 & 108,8 \\
\hline Araranguá & 125,7 & 111,7 & Canelinha & 134,5 & 119,4 \\
\hline Armazém & 126,6 & 112,4 & Canoinhas & 122,2 & 108,5 \\
\hline Arroio Trinta & 122,1 & 108,4 & Capão Alto & 119,0 & 105,7 \\
\hline Arvoredo & 130,8 & 116,2 & Capinzal & 126,4 & 112,3 \\
\hline Ascurra & 110,7 & 98,3 & Capivari de Baixo & 127,2 & 113,0 \\
\hline Atalanta & 108,1 & 96,0 & Catanduvas & 126,3 & 112,2 \\
\hline Aurora & 105,1 & 93,3 & Caxambu do Sul & 135,4 & 120,2 \\
\hline Bal. Arroio do Silva & 126,0 & 111,9 & Celso Ramos & 124,2 & 110,2 \\
\hline Bal. Barra do Sul & 147,4 & 130,9 & Cerro Negro & 120,5 & 107,0 \\
\hline Balneário Camboriú & 131,7 & 116,9 & Chapadão do Lageado & 108,4 & 96,3 \\
\hline Balneário Gaivota & 125,9 & 111,8 & Chapecó & 132,2 & 117,4 \\
\hline Balneário Piçarras & 134,0 & 119,0 & Cocal do Sul & 124,0 & 110,2 \\
\hline Balneário Rincão & 125,8 & 111,7 & Concórdia & 128,2 & 113,9 \\
\hline Bandeirante & 141,0 & 125,2 & Cordilheira Alta & 133,2 & 118,3 \\
\hline Barra Bonita & 139,5 & 123,9 & Coronel Freitas & 134,5 & 119,4 \\
\hline Barra Velha & 138,0 & 122,6 & Coronel Martins & 135,8 & 120,6 \\
\hline Bela Vista do Toldo & 122,0 & 108,3 & Correia Pinto & 114,7 & 101,8 \\
\hline Belmonte & 141,0 & 125,2 & Corupá & 129,7 & 115,1 \\
\hline Benedito Novo & 113,3 & 100,6 & Criciúma & 123,7 & 109,9 \\
\hline Biguaçu & 149,8 & 133,0 & Cunha Porã & 137,3 & 121,9 \\
\hline Blumenau & 120,2 & 106,7 & Cunhataí & 135,8 & 120,6 \\
\hline
\end{tabular}


Tabela 1. Continuação

\begin{tabular}{|c|c|c|c|c|c|}
\hline Município & $\begin{array}{l}P_{1 \text { dia }} \\
(\mathrm{mm})\end{array}$ & $\mathrm{I}_{15}\left(\mathrm{~mm} \mathrm{~h}^{-1}\right)$ & Município & $\begin{array}{c}P_{1 \text { dia }} \\
(\mathrm{mm})\end{array}$ & $\mathrm{I}_{15}\left(\mathrm{~mm} \mathrm{~h}^{-1}\right)$ \\
\hline Bocaina do Sul & 109,6 & 97,3 & Ipuaçu & 133,5 & 118,6 \\
\hline Curitibanos & 114,1 & 101,3 & Ipumirim & 130,2 & 115,6 \\
\hline Descanso & 139,5 & 123,9 & Iraceminha & 138,5 & 123,0 \\
\hline Dionísio Cerqueira & 141,1 & 125,3 & Irani & 127,7 & 113,4 \\
\hline Dona Emma & 107,5 & 95,5 & Irati & 136,2 & 120,9 \\
\hline Doutor Pedrinho & 115,4 & 102,5 & Irineópolis & 119,4 & 106,1 \\
\hline Entre Rios & 134,2 & 119,1 & Itá & 129,3 & 114,8 \\
\hline Ermo & 124,7 & 110,7 & Itaiópolis & 120,7 & 107,2 \\
\hline Erval Velho & 123,5 & 109,7 & Itajaí & 130,9 & 116,2 \\
\hline Faxinal dos Guedes & 131,1 & 116,4 & Itapema & 132,5 & 117,6 \\
\hline Flor do Sertão & 138,9 & 123,3 & Itapiranga & 139,6 & 124,0 \\
\hline Florianópolis & 157,2 & 139,6 & Itapoá & 145,9 & 129,6 \\
\hline Formosa do Sul & 135,8 & 120,6 & Ituporanga & 106,8 & 94,9 \\
\hline Forquilhinha & 123,2 & 109,4 & Jaborá & 127,2 & 112,9 \\
\hline Fraiburgo & 115,5 & 102,6 & Jacinto Machado & 124,9 & 110,9 \\
\hline Frei Rogério & 113,6 & 100,8 & Jaguaruna & 125,4 & 111,4 \\
\hline Galvão & 136,0 & 120,8 & Jaraguá do Sul & 136,1 & 120,8 \\
\hline Garopaba & 141,6 & 125,8 & Jardinópolis & 135,6 & 120,4 \\
\hline Garuva & 144,4 & 128,2 & Joaçaba & 125,2 & 111,1 \\
\hline Gaspar & 124,0 & 110,1 & Joinville & 144,4 & 128,2 \\
\hline Gov. Celso Ramos & 151,2 & 134,3 & José Boiteux & 109,0 & 96,8 \\
\hline Grão Pará & 120,5 & 107,0 & Jupiá & 137,0 & 121,6 \\
\hline Gravatal & 127,3 & 113,1 & Lacerdópolis & 125,4 & 111,3 \\
\hline Guabiruba & 120,4 & 106,9 & Lages & 116,6 & 103,6 \\
\hline Guaraciaba & 141,0 & 125,2 & Laguna & 129,6 & 115,1 \\
\hline Guaramirim & 144,6 & 128,4 & Lajeado Grande & 132,9 & 118,0 \\
\hline Guarujá do Sul & 141,1 & 125,3 & Laurentino & 106,4 & 94,5 \\
\hline Guatambu & 134,3 & 119,2 & Lauro Muller & 119,6 & 106,2 \\
\hline Herval D'Oeste & 123,0 & 109,2 & Lebon Régis & 115,5 & 102,6 \\
\hline Ibiam & 120,2 & 106,7 & Leoberto Leal & 116,7 & 103,6 \\
\hline Ibicaré & 122,4 & 108,7 & Lindóia Do Sul & 129,4 & 114,9 \\
\hline Ibirama & 106,9 & 94,9 & Lontras & 105,2 & 93,4 \\
\hline Içara & 124,8 & 110,8 & Luiz Alves & 134,5 & 119,5 \\
\hline Ilhota & 129,1 & 114,6 & Luzerna & 124,6 & 110,6 \\
\hline Imaruí & 131,3 & 116,6 & Macieira & 122,9 & 109,1 \\
\hline Imbituba & 134,4 & 119,4 & Mafra & 122,5 & 108,8 \\
\hline Imbuia & 109,7 & 97,5 & Major Gercino & 126,7 & 112,6 \\
\hline Indaial & 114,8 & 101,9 & Major Vieira & 123,1 & 109,3 \\
\hline Iomerê & 121,0 & 107,5 & Maracajá & 125,2 & 111,2 \\
\hline Ipira & 126,9 & 112,7 & Maravilha & 138,0 & 122,5 \\
\hline Iporã do Oeste & 139,4 & 123,8 & Marema & 134,0 & 119,0 \\
\hline
\end{tabular}


Tabela 1. Continuação

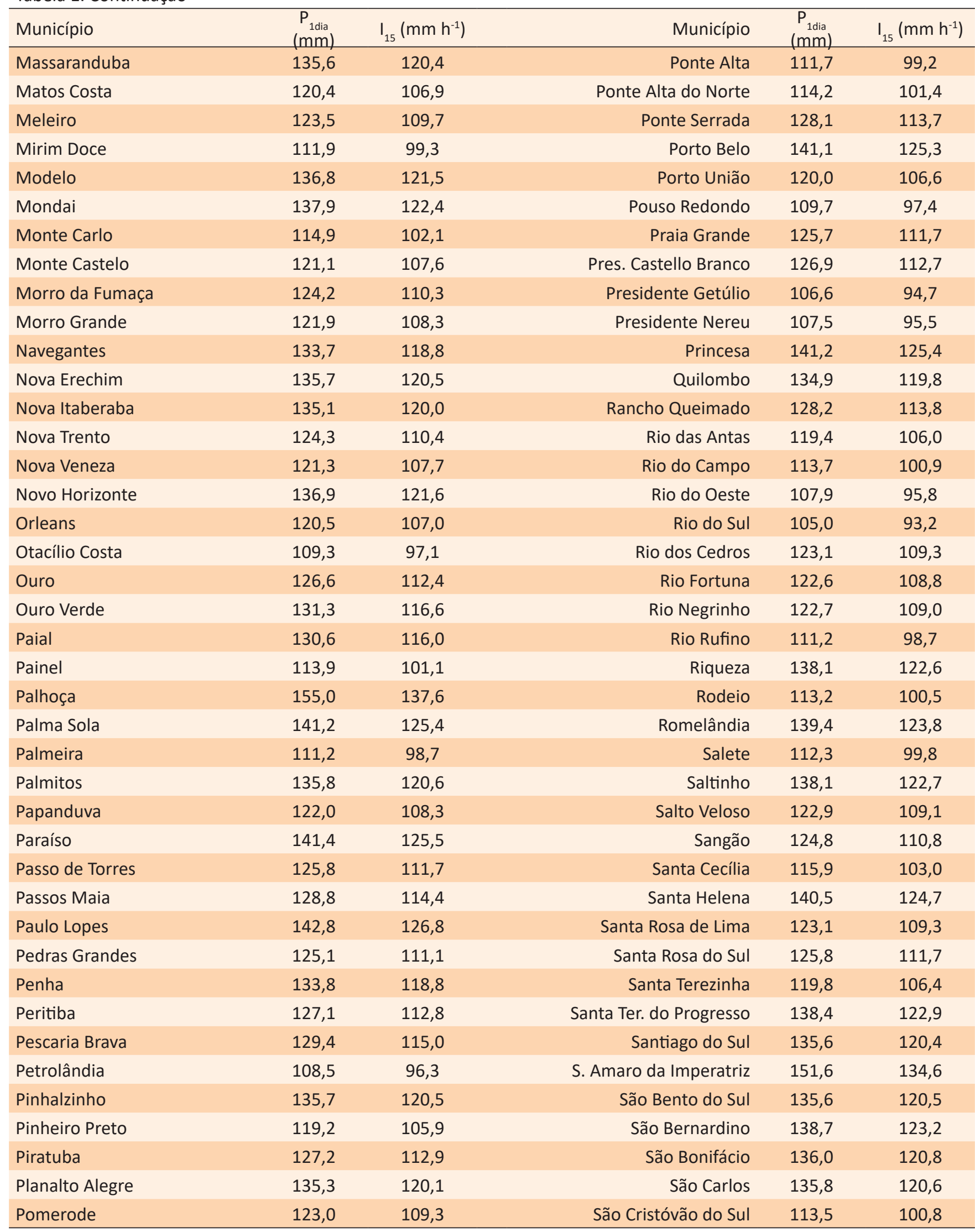

Continua.... 
Tabela 1. Continuação

\begin{tabular}{|c|c|c|c|c|c|}
\hline Município & $\begin{array}{c}P_{1 \text { dia }} \\
(\mathrm{mm})\end{array}$ & $\mathrm{I}_{15}\left(\mathrm{~mm} \mathrm{~h}^{-1}\right)$ & Município & $\begin{array}{c}P_{1 \text { dia }} \\
(\mathrm{mm})\end{array}$ & $\mathrm{I}_{15}\left(\mathrm{~mm} \mathrm{~h}^{-1}\right)$ \\
\hline São Domingos & 134,9 & 119,8 & Timbé do Sul & 122,3 & 108,6 \\
\hline São Francisco do Sul & 147,4 & 130,9 & Timbó & 117,2 & 104,0 \\
\hline São João Batista & 138,4 & 122,9 & Timbó Grande & 119,1 & 105,8 \\
\hline São João do Itaperiú & 141,1 & 125,3 & Três Barras & 122,9 & 109,2 \\
\hline São Joaquim & 116,9 & 103,8 & Treze Tílias & 123,2 & 109,4 \\
\hline São José & 152,9 & 135,7 & Trombudo Central & 106,5 & 94,5 \\
\hline São José do Cedro & 141,3 & 125,4 & Tubarão & 126,2 & 112,1 \\
\hline São José do Cerrito & 116,9 & 103,8 & Tunápolis & 140,0 & 124,3 \\
\hline São Martinho & 128,0 & 113,7 & Urubici & 114,9 & 102,0 \\
\hline S. Miguel da Boa Vista & 137,8 & 122,4 & Urupema & 112,5 & 99,9 \\
\hline São Miguel do Oeste & 140,7 & 125,0 & Urussanga & 123,4 & 109,6 \\
\hline São Pedro de Alcântara & 148,5 & 131,8 & Vargeão & 130,9 & 116,2 \\
\hline Saudades & 135,8 & 120,6 & Vargem & 119,8 & 106,4 \\
\hline Schroeder & 143,7 & 127,6 & Vargem Bonita & 126,7 & 112,5 \\
\hline Seara & 130,4 & 115,8 & Vidal Ramos & 110,4 & 98,1 \\
\hline Serra Alta & 137,7 & 122,2 & Videira & 119,6 & 106,2 \\
\hline Tijucas & 140,0 & 124,4 & & & \\
\hline
\end{tabular}

\section{Conclusões}

A espacialização dos valores de chuva máxima diária com período de retorno de 10 anos mostrou maiores valores nas regiões do Extremo Oeste catarinense e Litoral Centro e Norte, e menores valores no Alto Vale do Itajaí.

A chuva máxima diária média por município catarinense apresentou valores variando de 104,9 a $157,1 \mathrm{~mm}$.

A intensidade da chuva com duração de 15 minutos e período de retorno de 10 anos varia de 93,2 a $139,5 \mathrm{~mm} \mathrm{~h}^{-1}$.

\section{Referências}

Agência Nacional de Águas. Hidroweb: sistemas de informações hidrológicas. 2020. Available at: <http:// hidroweb.ana.gov.br>. Access on: Jun. 24, 2020.

ALMEIDA, C.O.S.; AMORIM, R.S.S.; ELTZ, F.L.F.; COUTO, E.G.; JORDANI, S.A. Erosividade da chuva em municípios do Mato Grosso: Distribuição sazonal e correlações com dados pluviométricos. Revista Brasileira de Engenharia Agrícola e Ambiental, v.16, n. 2, p.142- 152, 2012. DOI: https://doi. org/10.1590/S1415-43662012000200003.
ALVES SOBRINHO, T.; PERTUSSATTI, C.A.; REBUCCI, L.C.S.; OLIVEIRA, P.T.S. de; Estimativa da erosividade local das chuvas, utilizando redes neurais artificiais. Revista Ambiente \& Água, v.6, n. 2, p.246-254, 2011. DOI: http:// dx.doi.org/10.4136/ambi-agua.197

ASAE Standards. S268.5 JAN2012. Design, Layout, Construction and Maintenance of Terrace Systems. American Society of Agricultural Engineers, St. Joseph, Michigan. 2012. 10p.

BERTONI, J.; LOMBARDI NETO, F. Conservação do solo. São Paulo: Ícone, 2012. 335p. ๖ 
BACK, Á.J.; POLETO, C. Distribuição espacial e temporal da erosividade das chuvas no estado de Santa Catarina, Brasil. Revista Brasileira de Climatologia, v. 22, p.381-403, 2018. DOI: http://dx.doi.org/10.5380/abclima.v22i0.56914

BACK, Á.J. Chuvas intensas e chuva para dimensionamento de estruturas de drenagem para o Estado de Santa Catarina (com programa HidroChuSC para cálculos). Florianópolis, Epagri. 2013. 193p.

BACK, Á.J. Frequência de chuvas em Santa Catarina. Tecnologia e Ambiente, Criciúma, v.7, n.2, p. 63-72, 2001.

BACK, Á.J.; MIGUEL, L.P.; ZAMBRANO, G.J.D.; LADWIG, N.I. Variação espacial da chuva máxima diária no estado de Santa Catarina. Revista Iniciação Científica, Criciúma, v. 14, n. 1, p.59-72. 2016.

BESKOW, S.; CALDEIRA, T.L.; MELLO, C.R., FARIA L.C.; GUEDES, H.AS. Multiparameter probability distributions for heavy rainfall modeling in Extreme Southern Brazil. Journal of Hydrology: Regional Studies, v.4, p.123-133, 2015. DOI: https://doi.org/10.1016/j.

ejrh.2015.06.007

CETESB - COMPANHIA DE TECNOLOGIA DE SANEAMENTO AMBIENTAL. Drenagem urbana: manual de projetos. São Paulo. DAEE/ CETESB, 1986. 466p.

COAN, B.D.P.; BACK, Á.J.; BONETTI, A.V. Precipitação mensal e anual provável no estado de Santa Catarina. Revista Brasileira de Climatologia, v. 15, p. 122- 142, 2014. DOI: http://dx.doi.org/10.5380/abclima. v15i0.38348

CRUCIANI, D.E. A drenagem na agricultura. São Paulo: Ed. Nobel, 1989. 337 p.

DE MARIA, I.C.; DRUGOWICH, M.I.; BORTOLETTI, J.O.; VITTI, A.C.; ROSSETTO, R.; FONTES, J.L.; TCATCHENCO, J.; MARGATHO, S.F. Recomendações gerais para a conservação do solo na cultura da cana-de-açúcar. Campinas: Instituto Agronômico, Campinas, 2016. 100p. (Série Tecnologia APTA. Boletim Técnico IAC, 216).

DENARDIN, J.E.; KOCHHANN, R. A.; FLORES, C.A.; FERREIRA, T.N.; CASSOL, E.A.; MON-
DARDO, A.; SCHWARZ, R.A. Energia da gota de chuva e da enxurrada. In: DENARDIN, J.E.; KOCHHANN, R.A.; FLORES, C.A.; FERREIRA, T.N.; CASSOL, E.A.; MONDARDO, A.; SCHWARZ, R.A. Manejo da enxurrada em Sistema Plantio Direto. Porto Alegre: Fórum Estadual de Solo e Água, 2005. p.37-42.

EPAGRI. Empresa de Pesquisa Agropecuária e Extensão Rural de Santa Catarina. Banco de dados de variáveis ambientais de Santa Catarina. Florianópolis: Epagri, 2020. 20p. (Epagri. Documentos, 310).

FILLIBEN, J.J. The probability plot correlation coefficient test for normality. Technometrics. v.17, p.11-117, 1975.

GRIEBELER, N.P.; PRUSKI, F.F.; MARTINS JUNIOR, D.; SILVA, D.D. Avaliação de um modelo para a estimativa da lâmina máxima de escoamento superficial. Revista Brasileira de Ciência do Solo, Viçosa, v.25, n.2, p.411417, 2001.

GOTARDO, R.; PIAZZA, G.A.; TORRES, E.; SEVERO, D.L.; KAUFAMANN, V. Distribuição espacial e temporal das chuvas no estado de Santa Catarina. Geosul, Florianópolis, v.33, n.67, p.253-276, 2018. DOI: https://doi. org/10.5007/2177-5230.2018v33n67p253

HOSKING, J.R.M. L-moments: Analysis and Estimation of Distributions using Linear Combinations of Order Statistic. Journal of the Royal Statistical Society Series B, v.52, n.1, p.105-124, 1990.

KESSLER, J; RAAD, S.J. Análisis de dados pluviométricos. In: INTERNATIONAL FOR LAND RECLAMATION AND IMPROVEMENT. Principios y aplicaciones del drenaje. Wageningen, 1978. Publication 16, v.3, p.16-57.

KITE, G.W. Frequency and risk analyses in Hydrology. Water Resources publications. Colorado. 1978. 224 p.

LAFLEN, J.M.; MOLDENHAUER, W.C. Pioneering Soil Erosion Prediction: the USLE Story. WASWC, Thailand, 2003. 54p. (WASWC Special Publication n.1).

MARQUES, R. F. DE P.V.; MELLO, C.R.; SILVA, A. M.; CAMILA SILVA FRANCO, C.S.; OLIVEIRA, A.S. Desempenho de distribuições de probabilidades aplicadas a eventos extremos de precipitação diária. Ciênc. Agrotec., Lavras, v.38, n.4, p.335-342, 2014. DOI: https://doi. org/10.1590/S1413-70542014000400003.

MARRA, F.; MORIN, E.; PELEG, N.; MEI, Y.; ANAGNOSTOU, E.N. Intensity-duration-frequency curves from remote sensing rainfall estimates: comparing satellite and weather radar over the eastern Mediterranean. Hydrol. Earth Syst. Sci., v. 21, n.5, p. 23892404, 2017. DOI: https://doi.org/10.5194/ hess-21-2389-2017

MISTRY, P. B.; SURYANARAYANA, M. V. Estimation of Annual One Day Maximum Rainfall using Probability Distributions for Waghodia Taluka, Vadodara. Global Research and Development Journal for Engineering, p.296-300, 2019.

MONTEIRO, M. A. Caracterização climática do estado de Santa Catarina: uma abordagem dos principais sistemas atmosféricos que atuam durante o ano. Geosul, Florianópolis, v. 16, n.31, p. 69-78, 2001.

MONTEIRO, M.A.; FURTADO, S.M.de A. O clima no trecho Florianópolis - Porto Alegre: uma abordagem dinâmica. Geosul, n.19/20, p.116-133, 1995.

NAGHETTINI, M.; PINTO, E.J.A. Hidrologia Estatística. Belo Horizonte: CPRM, 2007. $552 p$.

ORSELLI, L. Clima. In: Atlas de Santa Catarina. Rio de Janeiro: Secretaria de Estado de Coordenação Geral e Planejamento, 1991. $96 p$.

RAMIREZ CRUZ, H.; VELASCO, O. L.; CASTILLO, L.A.I. Estimación mensual de intensidad de la lluvia en 30 minutos a partir de datos pluviométricos. Terra Latinoamericana, v.33, n.2, p.151-1159, 2015.

REBOITA, M. S.; GAN, M. A, ROCHA, R. P.; AMBRIZI, T. Regimes de precipitação na América do Sul: Uma revisão bibliográfica. Revista Brasileira de Meteorologia, v.25, n. 2, p.185-204, 2010.

SCHWAB, G.O.; FREVERT, R.K.; DMINSTER, T.W. \& BARNES, K.K. Soil and water conservation engineering. 2. ed. New York: John Wiley, 1966. 683p. (The Ferguson Foundation Agricultural Engineering Series). 